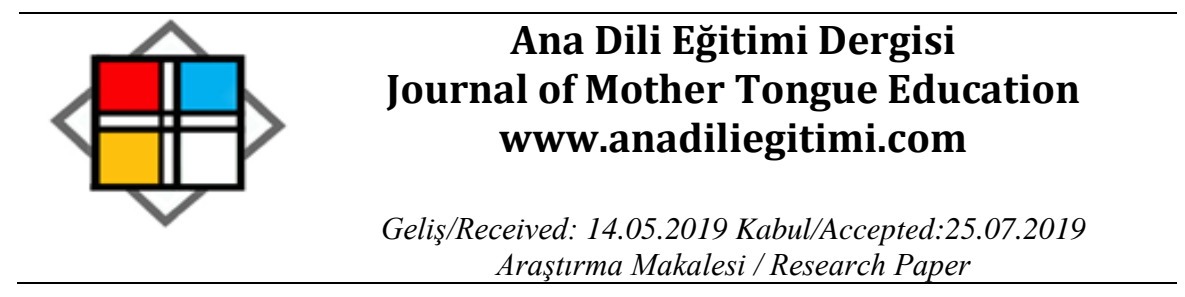

\title{
Neden Bir Çocuk Dili Derlemine İhtiyacımız Var?
}

\begin{abstract}
Özay KARADA $\breve{G}^{*}$
Öz

Bir dilin gerek ana dili gerekse yabancı dil olarak öğretiminde sıklık çalışmaları önemli bir yer tutar. Sıklık belirli bir amaçla derlenen dil içeriklerinde aynı dilsel olgu veya birimin gerçekleşme sayısı olarak tanımlanmaktadır. Sıklık çalışmaları genel olarak bir dildeki bütün çeşitliliği içeren genel derlemler veya edebiyat, hukuk vb. gibi bilim alanları; roman, gazete yazıları vb. gibi türler; bir eğitim seviyesindeki öğrenciler, bir meslek grubu vb. gibi toplumun bir kesimine yönelik özel derlemler şeklinde gerçekleştirilmektedir. Genel derlemlerden elde edilen sıklık listeleri, dilin sıklık bakımından genel durumunu ortaya koymaktadır. Genel derlemlerden elde edilen sıklık listelerindeki kelimelerin bir bölümünün, çocukluk çağında bulunan okul öncesi, ilkokul ve ortaokul öğrencilerine öğretilmesi güçtür. Ayrıca bu listelerle öğrencilere okutulacak metinlerin üretilmesi veya seviyelendirilmesi bazı sorunlar yaratmaktadır. Bu açıdan çocuk dilin kullanım sıklığının bilinmesi son derece önemli hâle gelmektedir. Bu çalışmada Türkçe için tasarlanmış genel bir derlemden elde edilen en sık 1000 kelime ile temel eğitim düzeyindeki çocukların yazılı anlatımlarından elde edilen en sık 1000 kelime karşılaştırılmaktadır. Karşılaştırmada 535 kelimenin her iki listede ortak olduğu belirlenmiş, temel eğitim düzeyindeki öğrencilerin ve derlem listesinin farklılaşan kelimeleri ayrı ayrı listelenmiştir. Elde edilen sonuçlar çocuk dilinden derlenecek içeriklerle, bir çocuk dili derlemi oluşturulması zorunluluğunu ortaya koymaktadır.
\end{abstract}

Anahtar Kelimeler: Kelime kullanım sıklığı, derlem, çocuk dili derlemi, temel eğitim, ana dili eğitimi.

Why Do We Need Child Language Corpus?

\begin{abstract}
Frequency studies are important in teaching mother tongue and foreign language. Frequency is defined as the number of occurrences of the same linguistic phenomenon or unit in language contents compiled for a specific purpose. Frequency studies generally include general corpus involving all the diversity in a language or literature, law, etc. science fields such as; novels, newspaper articles and etc. students at an educational level, a professional group, and etc. private corpus for a segment of society. The frequency lists obtained from the ordinary corpus show the general status of the language in terms of frequency. Some words in the frequency lists obtained from general corpus make it difficult to produce or level the texts to be read for pre-school, primary and secondary students. In this respect, it is very important to know the frequency of child language usage. In this study, the most common 1000 words obtained from a general corpus designed for Turkish and 1000 words obtained from the written expressions of children at basic education level were compared. When two lists were compared, 535 words were found to be common in both lists, and the different words of the students at the basic education level and the collection list were listed separately. Findings show the necessity of creating a child language corpus with the contents to be compiled from the child language.
\end{abstract}

Keywords: Word usage frequency, corpus, child language corpus, basic education, mother tongue education.

\footnotetext{
* Doç. Dr, Hacettepe Üniversitesi Eğitim Fakültesi Türkçe ve Sosyal Bilimler Eğitimi Bölümü, Ankara, ozaykaradag@hacettepe.edu.tr, ORCID: 0000-0003-4596-1203
} 


\section{Giriş}

Bir dilin gerek ana dili gerekse yabancı dil olarak öğretiminde sıklık çalışmaları önemli bir yer tutar. Sıklık, "belli uzunlukta bir konuşma ya da yazıda aynı dilsel olgu ya da birimin gerçekleşme sayısı" olarak tanımlanmaktadır (Vardar, 2002). Bir sıklık çalışmasında, seçilen içerikteki birimlerin tekrarlanma sayıları belirlenerek bir liste oluşturulması hedeflenir ve elde edilen liste en yüksek sıklığa sahip unsurdan en az sıklığa sahip olan unsura doğru ilerler.

Belirli bir öğrenci grubunun, bir toplumsal kesimin, bir kitabın veya genel olarak bir dilin söz varlığı üzerine yapılan araştırmaların büyük bir bölümünü sıklık çalışmaları oluşturur (Çifci, 1991; Göz, 2001; Karadağ, 2005; Kurudayığlu, 2005; Yazı, 2005; Yiğittürk, 2005; Baş, 2006; Karadağ ve Kurudayıoğlu, 2006; Pilav, 2008; Aksan vd., 2017). Sıklık çalışmaları bir dilde, bir zümrede (bir meslek grubunun üyelerinin, bir yaş grubundaki öğrencilerin, ilkokul veya ortaokul gibi bir eğitim düzeyindeki öğrencilerin yazılı ve sözlü anlatımları vb.) veya bir eserde bazı dil birimlerin diğerlerinden daha sık kullanıldığı gerçeğinden hareket ederek incelenen içeriği, içerdiği birimlerin sık kullanılma durumları açısından betimler.

Bütün diller için geçerli olmak üzere, bir dilde en sık kullanılan ilk 1000 kelime o dille yapılan üretimlerin yaklaşık \% 80'ini karşılar (Aksan 2000). Bu durum bir kitaptan veya bir toplumsal gruptan derlenen içerik üzerine yapılan çalışmalarda da benzerdir. İngilizce için yapılan çalışmada (Nation 1990'dan akt. Lipinski 2010) en sık kullanılan 4.000-5.000 kelimenin yazılı bir metnin \% 95'ini, en sık kullanılan 1.000 kelimenin ise konuşmanın \% 85'ini oluşturduğu belirtilmektedir.

Sıklık çalışmalarının en gelişmişmiş biçimi kuşkusuz bilgisayar aracılığıyla oluşturulan derlemlerdir. Doğal dil işleme yazılımları ile gerçekleştirilen derlemler büyük hacimli çalışmalardır. Derlem çalışmasında işlenen içeriğin hacmi ne kadar büyürse ortaya çıkan sıklık sonucu o kadar güvenilir olmaktadır. Bu bakımdan derlem çalışmaları dil öğretimi bakımından referans oluşturmaktadır.

Derlemler genel ve özel olmak üzere ikiye ayrılır. Genel derlemler bir dildeki bütün alt çeşitliliği içeren (Tahiroğlu, 2010) bu yönüyle dilin bütünü hakkında bir görünüm ortaya koyan derlemlerdir. Özel derlemler ise hukuk, tıp, edebiyat vb. alanlara ve gazete, roman, dergi, akademik yazılar gibi türlere özgüdür (Tahiroğlu, 2010). Seçilen türlere bağlı olarak genel derlemlerin temsil güçleri artıp eksilirken özel derlemlerin temsil gücü içerdikleri sözcük düzeyi ile sınırlıdır (Mc Enery vd. 2006'den akt. Tahiroğlu, 2010). Genel bir derlem türü olan referans derlemler, dilin belirli bir döneminden kesit olarak derlenen içeriği farklı kategorilere göre etiketleyen ve kullanıcılara buna bağlı arama imkânı veren tasarımları bakımından son derece önemlidir. İngilizce için hazırlanan British National Corpus (BNC) (https://www.english-corpora.org/bnc/) ile aynı ilkelerle hazırlanan Türkçe Ulusal Derlemi (TUD) 


\section{Neden Bir Çocuk Dili Derlemine İhtiyacımız Var?}

(https://www.tnc.org.tr) referans derlemlerin örnekleri olarak verilebilir. Genel derlemlerin bir diğer türü de monitör derlemlerdir. İçeriği sürekli gelişen ve genişleyen bu türde, malzemesi örneklemeyle elde edilen genel derlemler gibi durağan (statik) yapı söz konusu değildir ve metin yığınları yıllık, aylık ve hatta günlük olarak değerlendirilip ön işlemlerden geçmek üzere ham olarak toplanıp işlenerek derleme dâhil olur (Tahiroğlu, 2010).

Derlemlerden elde edilen sıklık listeleri özellikle yabancı dil öğretiminde temel bir referanstır. Dilin genel amaçlı olarak öğretiminde derlem temelli sıklık listelerinin veya sıklık sözlüklerinin kullanılması son derece işlevseldir. Genel yaklaşım dilde en sık kullanılan birimlerin öncelikli olarak öğretiminin hedeflenmesidir. Bu noktada derlemden elde edilen en sık 1000 ila 2000 kelime işlevsel olarak kullanılır. Ancak genel derlemler dilin genel görünümünü ortaya koyar ve bu görünüm alt yaşlarda (okul öncesi ve temel eğitim düzeyi) bulunan çocuklara öğretilecek kelimeler söz konusu olduğu zaman gelişim özelliklerine aykırılıklar oluşturur. Özellikle ana dili eğitiminin yapııdığı okul öncesi ve ilkokul düzeyinde soyut düşünce gelişimi henüz gerçekleşmeyen çocuklar için genel derlem sıklık listeleri birçok soyut kelime içerir. Ortaokul düzeyinde soyut düşünme becerisi geliştiğinden çocuklar için durum daha az sorunlu olsa da bu yaş çocuklarının gündemi de dilin genel kullanımından farklılıklar gösterir. Bu sebeplerden dolayı okul öncesi ve temel eğitim düzeyindeki çocuklar için gerek kelime öğretimi açısından gerekse bu çocuklara okutulacak metinlerin üretilmesi veya seviyelendirilmesi bakımından özel derlem ihtiyacı oluşmaktadır.

Çocukların anlatımlarından oluşturulan sıklık listeleri ile çocuk edebiyatı ürünlerinden elde edilen sıklık listelerinin karşılaştırılmasında da ortaklığın beklenenden düşük olduğu görülmektedir. Baş (2006) çalışmasında ilköğretim birinci kademe öğrencilerinin sıklık listesi (Karadağ, 2005) ile ilköğretim ikinci kademe öğrencilerinin sıklık listesini (Kurudayıoğlu, 2005) birleştirerek ilköğretim öğrencilerinin sıklık listesini elde etmiş, bu sıklık listesinin ilk 2000 kelimesi ile çocuk edebiyatı eserlerinden elde ettiği sıklık listesinin ilk 2000 kelimesini karşılaştırmıştır. Karşılaştırmada 1260 kelimenin her iki listede bulunduğu tespit edilmiştir. Buna karşıık çocukların en sık kullandığı ilk 2000 kelimeden 740'ının çocuk kitaplarından elde edilen sıklık listesinin ilk 2000 kelimesi arasında yer almadığı ve farklılı̆ın \%37 oranında olduğu sonucuna ulaşılmıştır.

Çocuk kitapları, hedef kitlesinin özelliklerini dikkate alması ve bu bakımdan çocuklara uygun temaları içermesine rağmen söz varlığı bakımından zikredilen farklılaşma oldukça ilginçtir. Bu durum çocuk kitaplarından elde edilen sıklık sonuçlarının da çocuklara öğretilecek kelimelerin belirlenmesinde, okutulacak metinlerin üretilmesi ve seviyelendirilmesinde doğrudan kullanılamayacağı sonucunu ortaya koymaktadır. Bu açıdan bakıldığında en geçerli yol çocuk diline özgü özel bir derlemin oluşturulmasıdır. Özellikle temel eğitim çağındaki çocukların hem yazılı hem de sözlü dilinden geniş ölçekli katılımla oluşturulacak bir özel derlem işlevsel olabilir. Temel eğitim düzeyindeki 
çocuk sayısını temsil edebilecek bir örneklemle yapılacak bir çalışmadan elde edilecek sıklık listeleri, bu yaş düzeyindeki tüm çocuklara öğretilecek kelimelerin belirlenmesinde, yine bu düzeydeki çocuklara okutulacak kitapların ve metinlerin hem üretiminde hem de var olan kitapların ve metinlerin seviyelendirilmesinde önemli bir referans oluşturacaktır.

Bu çalışmada, çocuk dilinin kendine özgülüğünü ortaya çıkaracak şekilde, genel amaçlı bir Türkçe derleminden elde edilen sıklık listesinin ilk 1000 kelimesi ile temel eğitim düzeyinde öğrenim gören çocukların anlatımlarından elde edilen sıklık listesinin ilk 1000 kelimesi karşılaştırımaktadır. Çalışmada karşılaştırılan listelerin ortak ve farklı kelimeleri hem sayısal değerleri hem de ayrı ayrı alfabetik listeleriyle sunulmaktadır.

\section{Yöntem}

Çalışmada temel eğitim düzeyindeki öğrencilerin en sık kullandıkları 1000 kelime ile derlem temelli oluşturulmuş sıklık sözlüğünün ilk 1000 kelimesi karşılaştırılmıştır. Temel eğitim düzeyindeki öğrencilere ait sıklık listesi Karadağ’ın (2018) Kelime Öğretimi kitabında yer alan 1250 kelimelik “Hedef Kelime Listesi"nin ilk 1000 kelimesi esas alınarak oluşturulmuştur. "Hedef Kelime Listesi" temel eğitim düzeyindeki öğrencilerin yazılı anlatımlarından oluşturulmuş sıklık listesidir. Liste, Karadağ (2005) ve Kurudayıoğlu'nun (2005) sıklık çalışmalarının metin havuzları birleştirilerek oluşturulmuştur. Toplam 4.861 öğrencinin yazılı anlatımlarından elde edilen metin havuzu 392.494 kelimeden oluşmaktadır. Derlem temelli en sık 1000 kelime Aksan ve arkadaşlarının (2017) A Frequency Dictionary of Turkish (Türkçe Sıklık Sözlüğü) adlı çalışmalarından alınmıştır. Bu çalışma 50 milyon kelimelik Türkçe Ulusal Derlemi (http://www.tnc.org.tr) temelli olarak hazırlanmış yazılı ve sözlü Türkçe en sık kullanılan 5000 kelimeyi içeren bir sıklık sözlüğüdür.

Bulgular iki farklı listenin karşılaştırılmasından elde edilmiştir. Illk olarak her iki listede ortak olan kelimeler belirlenmiştir. İkinci olarak temel eğitim düzeyindeki öğrencilerin (1-8. sınıflar) en sık kullandığı 1000 kelime içinde bulunan ancak derlem temelli en sık 1000 kelime içinde yer almayan kelimeler belirlenmiştir. Üçüncü olarak derlem temelli en sık 1000 kelime içinde yer alan ancak temel eğitim düzeyindeki öğrencilerin (1-8. sınıflar) en sık kullandığı 1000 kelime içinde yer almayan kelimeler belirlenmiştir. Elde edilen sonuçlar yorumlanarak doğrudan raporlaştırılmıştır.

\section{Bulgular ve Yorum}

Ilköğretim 1-8. sınıf öğrencilerinin en sık kullandığı 1000 kelime (Karadağ, 2018) ile Türkçe Sıklık Sözlüğü’nde (Aksan vd., 2017) yer alan ilk 1000 kelime karşılaştırılmıştır. Karşılaştırma sonucunda her iki listede yer alan ortak kelimelerin sayısının 535 olduğu tespit edilmiştir. Bu değer iki sıklık listesi arasındaki uyumun \%53,5 düzeyinde olduğunu ortaya çıkarmaktadır. Tersten bakıldığında her iki 
listenin birbirinden \%46,5 oranında farklılaştığı görülmektedir. Aşağıda her iki listede ortak olan 535 kelime alfabetik olarak verilmiştir:

Ortak Kelime Listesi (Alfabetik)

\begin{tabular}{|c|c|c|c|}
\hline acaba & bağır- & bölüm & derin \\
\hline $\mathrm{aCl}$ & bağla- & böyle & ders \\
\hline açık & bağlı & böylece & dert \\
\hline aç- & bahçe & bu & devlet \\
\hline ad & bak- & bugün & dış \\
\hline ada & balık & bul- & dışarı \\
\hline adam & bas- & bura & diğer \\
\hline ağaç & baş & bütün & dil \\
\hline ağız & başarı & büyük & dinle- \\
\hline ağla- & başarılı & büyü- & diş \\
\hline aile & başar- & can & diye \\
\hline akıl & başka & canlı & doğa \\
\hline akşam & başla- & cevap & doğ- \\
\hline alan & bazen & ceza & doğru \\
\hline alış- & bazı & çaba & doktor \\
\hline al- & bebek & çağır- & dolaş- \\
\hline alt & bekle- & çalış- & dolayı \\
\hline ama & belirle- & çal- & dönem \\
\hline amaç & belki & çarp- & dön- \\
\hline an & ben & çay & dur- \\
\hline ana & benze- & çek- & durum \\
\hline ancak & beraber & çeşitli & duvar \\
\hline anlam & beri & çevre & duygu \\
\hline anla- & besle- & çık- & duy- \\
\hline anlat- & beyaz & çiçek & dünya \\
\hline anne & bırak- & çiz- & düşman \\
\hline ara & bile & çocuk & düş- \\
\hline araba & bilgi & çoğu & düşünce \\
\hline araç & bilgisayar & çok & düşün- \\
\hline arka & bil- & çöz- & düzenle- \\
\hline arkadaş & bina & çünkü & eğer \\
\hline artık & bin- & da & eğitim \\
\hline asker & bir & dağ & el \\
\hline aslında & biraz & daha & emin \\
\hline aşağı & birbiri & dakika & en \\
\hline ata & birçok & dal(ağaç) & erkek \\
\hline ateş & birden & davranış & erken \\
\hline atla- & biri & davran- & eser \\
\hline at- & birinci & defa & eski \\
\hline ay(zaman) & birkaç & değer & eş \\
\hline ayak & birlikte & değerli & etkile- \\
\hline aynı & bit-(tükenmek) & değil & et- \\
\hline ayrı & biz & değişik & etraf \\
\hline ayrıca & boş & değiş̧- & ev \\
\hline az & boy & de- & evet \\
\hline baba & boyunca & deniz & evlen- \\
\hline
\end{tabular}




\begin{tabular}{|c|c|c|c|}
\hline fakat & hayat & karanlık & neden \\
\hline fark & hayır & karar & nere \\
\hline farklı & hayvan & kardeş & niye \\
\hline fazla & hazırla- & karı & 0 \\
\hline fikir & hedef & karşıla- & oda \\
\hline film & hem & kaybet- & oğul \\
\hline fotoğraf & hemen & kay- & okul \\
\hline gece & hep & kaza & oku- \\
\hline geç- & her & kazan- & olay \\
\hline gelecek & herkes & kenar & ora \\
\hline gel- & hızlı & kendi & orman \\
\hline gemi & hiç & kere & orta \\
\hline genç & hiçbir & kes- & otel \\
\hline genellikle & hisset- & kez & otur- \\
\hline gerçek & hoca & kır- & oyna- \\
\hline gerçekten & hoş & kırmızı & oyun \\
\hline geri & ışık & kısa & öğrenci \\
\hline getir- & iç & kız & öğren- \\
\hline gez- & içeri & kim & öğret- \\
\hline gibi & için & kimi & öğretmen \\
\hline gir- & ihtiyaç & kimse & öl- \\
\hline git- & ikinci & kişi & ölüm \\
\hline giy- & il & kişilik & ön \\
\hline gönder- & ilaç & kitap & önce \\
\hline göre & ile & kol & önem \\
\hline gör- & ileri & konu & önemli \\
\hline göster- & ilerle- & konuş- & örneğin \\
\hline götür- & ilgi & kork- & örnek \\
\hline grup & ilgilen- & korku & öykü \\
\hline gül & ilgili & koru- & öyle \\
\hline gün & ilk & koş- & özellik \\
\hline güneş & i- & koy- & özellikle \\
\hline günlük & inan- & kötü & para \\
\hline güven & in- & köy & parça \\
\hline güzel & insan & kulak & par- \\
\hline güzellik & isim & kullan- & paylaş- \\
\hline haber & istek & kural & pazar \\
\hline hafta & iste- & kur- & pek \\
\hline hak & iş & kurtar- & pencere \\
\hline hal & iyi & kurtul- & plan \\
\hline hala & izin & kuş & polis \\
\hline halk & izle- & küçük & rağmen \\
\hline hangi & kaç & masa & renk \\
\hline hanım & kadar & mektup & resim \\
\hline hareket & kadın & mesela & roman \\
\hline hasta & kafa & meslek & saat \\
\hline hastane & kaldır- & mutlaka & sabah \\
\hline hata & kalk- & mutlu & saç \\
\hline hatırla- & kal- & müdür & sadece \\
\hline hatta & kalp & müzik & sağ \\
\hline hava & kan & nasıl & sağla- \\
\hline hayal & kapı & ne & sahip \\
\hline
\end{tabular}




\begin{tabular}{|c|c|c|c|}
\hline sakla- & sorumlu & top & yanlış \\
\hline sanki & sorun & topla- & yap- \\
\hline sar- & söyle- & toplum & yara \\
\hline sat- & söz & toprak & yardım \\
\hline savaş & spor & tut- & yarı \\
\hline saygı & su & tüm & yaş(ömür) \\
\hline sayı & süre & uçak & yaşam \\
\hline say- & sürekli & uğra- & yaşa- \\
\hline seç- & sür- & uğraş- & yaşlı \\
\hline sefer & şarkı & ulaş- & yatak \\
\hline sen & şehir & unut- & yat- \\
\hline sene & şekil & uyan- & yazar \\
\hline ses & şey & uyku & yazı \\
\hline sevgi & şiir & uyu- & yaz- \\
\hline sevgili & şimdi & uzak & ye- \\
\hline sev- & şöyle & uzun & yeni \\
\hline seyret- & şu & ülke & yeniden \\
\hline sıcak & tabii & üniversite & yer \\
\hline sıkıntı & takım & üst & yeşil \\
\hline sınav & tak- & üzere & yet- \\
\hline sinıf & tam & üzeri & yıl \\
\hline sıra & tamam & üz- & yine \\
\hline sigara & tane & vakit & yok \\
\hline silah & tanı- & var & yol \\
\hline sil- & taraf & varlık & yön \\
\hline sinema & tarih & ve & yukarı \\
\hline siz & tarz & veya & yurt \\
\hline soğuk & taş & vur- & yüksek \\
\hline sokak & taşı- & yabancı & yürü- \\
\hline sok- & tek & yakala- & yüz(çehre) \\
\hline sol & tekrar & yakın & zaman \\
\hline son & telefon & yaklaş- & zarar \\
\hline sonra & televizyon & yak- & zaten \\
\hline sonuç & temel & yalnız & zengin \\
\hline sor- & tepe & yan & zor \\
\hline soru & tiyatro & yani & \\
\hline
\end{tabular}

Ortak kelimeler listesi incelendiğinde listenin dilin işletimi bakımından kaçınılmaz olarak kullanılan edatları, bağlaçları, zarfları, şahıs zamirlerini, temel sıfatları, temel ihtiyaçlar ve gündelik yaşamla ilgili olgu ve varlıkları karşılayan kelimeleri içerdiği görülmektedir.

1-8 sınıf öğrencilerinin kullandığı en sık 1000 kelime içinde yer alan (Karadağ, 2018) ancak Türkçe Sıklık Sözlüğü’ndeki (Aksan vd., 2017) ilk 1000 kelime içinde yer almayan 465 kelime aşağıda alfabetik olarak verilmiştir: 
Sadece Öğrencilerde Bulunan Kelimeler (Alfabetik)

\begin{tabular}{|c|c|c|c|}
\hline abla & bayıl- & dilek & gelin \\
\hline acık- & bayram & dile- & gelme \\
\hline açıl- & beğen- & dinlen- & gene \\
\hline adlı & belirt- & doğum günü & gerek- \\
\hline ağabey & bence & dokuz & gezdir- \\
\hline ağlama & beşinci & doldur- & gezi \\
\hline ak- & bilebil- & dolu(yağış) & gezme \\
\hline akraba & bir kere & dondurma & gidil- \\
\hline alabil- & bir sürü & dost & gitme \\
\hline alın- & bir şey & dostluk & giyin- \\
\hline alışveriş & bir tane & dördüncü & giysi \\
\hline alma & bisiklet & dört & gol \\
\hline altın & bitir- & döv- & göl \\
\hline altıncı & boylu & duygusal & görebil- \\
\hline amca & buçuk & düğün & görme \\
\hline ameliyat & bulabil- & dükkân & görün- \\
\hline anı & bulaşık & dürüst & göz \\
\hline anlaş- & bulma & düzenli & gözlü \\
\hline anlatabil- & bulun- & ebe & gül- \\
\hline anlatma & bunlar & ebele- & güven- \\
\hline anlat- & cam & edin- & hadi \\
\hline anneanne & cami & eğlenceli & hakkında \\
\hline apartman & cennet & eğlen- & harika \\
\hline arama & civciv & ek- & hastalan- \\
\hline ara- & cumartesi & elbise & havuz \\
\hline arkadaşlık & çabuk & elma & hayvanat bahçesi \\
\hline arkadaş ol- & çalışkan & emek & hazırlan- \\
\hline art & çalışma & enişte & hâlâ \\
\hline asla & çanta & en çok & hediye \\
\hline aslan & çarşı & erik & hele \\
\hline at & çekil- & erkenden & hep beraber \\
\hline atıl- & çektir- & ertesi & her gün \\
\hline atlama & çeşme & eskiden & her şey \\
\hline atma & çıkar- & eşek & her zaman \\
\hline $\mathrm{avcl}$ & çıkart- & eşya & heyecan \\
\hline ay & çizgi film & et & heyecanlı \\
\hline ayakkabı & çoban & evcilik & heykel \\
\hline ayı & çöp & evvel & hırsız \\
\hline ayna & dalga & ev işi & hiç kimse \\
\hline ayrıl- & dal- & fakir & hikâye \\
\hline babaanne & dayanabil- & fare & horoz \\
\hline bacak & dayı & fark et- & huy \\
\hline bakkal & dede & fındık & huzur \\
\hline bakma & değiştir- & fırçala- & ISIr- \\
\hline balkon & dere & futbol & iç- \\
\hline baraj & ders yap- & futbolcu & iki \\
\hline bardak & dev & geç & ilçe \\
\hline barış- & devam et- & geçen & ilkönce \\
\hline basketbol & dikiş & geçin- & indir- \\
\hline & dikkatli & geçir- & inek \\
\hline
\end{tabular}




\begin{tabular}{|c|c|c|c|}
\hline inşallah & koyul- & otobüs & sevin- \\
\hline ip & koyun & oynama & sevme \\
\hline işte & köpek & oynan- & sıkıl- \\
\hline işyeri & köprü & oyuncak & sır \\
\hline iyice & körebe & oyuncu & sırt \\
\hline iyileş- & kötülük & o sırada & sinirlen- \\
\hline iyilik & köylü & öbür & siyah \\
\hline iyi kalpli & kral & ödev & sobele- \\
\hline kabul et- & kraliçe & öğle & sofra \\
\hline kaçır- & kum & öldür- & sonradan \\
\hline kaç- & kurbağa & önceden & sonunda \\
\hline kahvaltı & kurt & önlük & süpür- \\
\hline kahverengi & kuyu & öp- & süt \\
\hline kalabalık & kuzen & ördek & şaka \\
\hline kale & kuzu & öt- & şaşır- \\
\hline kaleci & küçüklük & özle- & şeker \\
\hline kalma & küs- & özür & şelale \\
\hline kalpli & leylek & padişah & şirin \\
\hline kapan- & lise & park & tabak \\
\hline kapat- & lokanta & peki & tahta \\
\hline kaplumbağa & maç & peri & takıl- \\
\hline karın & maç yap- & peş & tanış- \\
\hline karne & mağara & piknik & tarihî \\
\hline karşı & mahalle & piknik yap- & tarihî eser \\
\hline karşılaş- & manzara & pişir- & tarla \\
\hline karşılık & matematik & prens & taşın- \\
\hline kar(yağış) & mavi & rüya & tatil \\
\hline kasaba & maymun & sabahleyin & tatlı \\
\hline katıl- & melek & saçlı & tavşan \\
\hline kavga & mendil & sağlam & tavuk \\
\hline kavga et- & merak et- & saha & temiz \\
\hline kaya & merdiven & sahil & temizle- \\
\hline kaybol- & meyve & saklambaç & temizlik \\
\hline kazan & mezar & saklan- & teneffüs \\
\hline kâğıt & mimar & salıncak & test \\
\hline keçi & mutfak & sallan- & teşekkür et- \\
\hline kedi & mutluluk & san- & teyze \\
\hline kesil- & mutlu ol- & saray & tilki \\
\hline keşke & müze & sarı & toplama \\
\hline kırıl- & neyse & sarıl- & toplan- \\
\hline kısaca & nine & savaş- & toz \\
\hline kış & not & sayesinde & trafik \\
\hline kıyafet & odun & saygılı & tren \\
\hline kıуı & oğlan & sebze & turist \\
\hline kız- & okuma & sekiz & türlü \\
\hline kocaman & olabil- & serçe & tüy \\
\hline koca(eş) & olma & servis & uç- \\
\hline komik & ol- & sevecen & uçurtma \\
\hline komşu & on & sevil- & um- \\
\hline konuşma & onlar & sevimli & unutabil- \\
\hline koşma & on beş & sevinç & üçüncü \\
\hline kovala- & ot & sevinçli & üzgün \\
\hline
\end{tabular}




$\begin{array}{llll}\text { üzül- } & \text { yapma } & \text { ya da } & \text { yılan } \\ \text { üzüntü } & \text { yaramaz } & \text { ya(ünlem) } & \text { yirmi } \\ \text { var- } & \text { yardımcı ol- } & \text { yedi } & \text { yiyecek } \\ \text { veril- } & \text { yardım etme } & \text { yeğen } & \text { yolculuk } \\ \text { ver- } & \text { yardım et- } & \text { yem } & \text { yorul- } \\ \text { voleybol } & \text { yarım } & \text { yeme } & \text { yum- } \\ \text { ya } & \text { yarın } & \text { yemek(aş) } & \text { yumurta } \\ \text { yağ- } & \text { yarış } & \text { yemyeşil } & \text { yuva } \\ \text { yağmur } & \text { yavaş yavaş } & \text { yenge } & \text { yüzme } \\ \text { yakalamaca } & \text { yavru } & \text { yen- } & \text { yüz- } \\ \text { yalan } & \text { yayla } & \text { yerden yüksek } & \text { zevk } \\ \text { yan- } & \text { yaz } & \text { yeşillik } & \text { zevkli } \\ \text { yapabil- } & \text { yazııı } & \text { yıka- } & \text { zil } \\ \text { yapıl- } & \text { yazın } & \text { yıkı- } & \text { zorluk }\end{array}$

1-8 sınıf öğrencilerinin en sık kullandığı 1000 kelime içinde yer alan hayvan adlarının (hayvanat bahçesi, eşek, inek, kurbağa, serçe, kaplumbağa, köpek, tavşan, at, tavuk, civciv, horuz, aslan, ayı, tilki, fare, keçi, kedi, kurt, kuzu, leylek, maymun); oyun ve sporla ilgili (yerden yüksek, ebe, yarış, saklambaç, yakalamaca, sobelemek, körebe, evcilik, oynama, oyuncak, oyuncu, park, salıncak, futbol, maç, kale, kaleci, gol, voleybol, basketbol); arkadaşlık ve duygularla ilgili (dost, dostluk, güvenmek, arkadaş, özlemek, duygusal, sevmek, sevecen, sevimli, eğlence, eğlenceli, eğlenmek, gülmek, şaka, komik, heyecan, iyilik, sevinç, sevimli) yiyeceklerle ilgili (sofra, yiyecek, sebze, süt, kahvaltı, yumurta, dondurma, şeker, elma, erik, fındık); okul ve eğitimle ilgili (ders, karne, okuma, ödev, önlük, teneffüs, test, matematik) ve masal dünyasına ait (padişah, kral, kraliçe, prens, saray) kelimelerin sayısının çokluğu dikkat çekicidir. Derlem temelli sıklık listesinde en sık 1000 kelime içinde yer almayan bu kelimeler çocuk dünyasının kendine özgülüğünü ortaya koymaktadır.

Türkçe Sıklık Sözlüğü'nde (Aksan vd., 2017) ilk 1000 kelime içinde yer alan, buna karşılık 1-8 sınıf öğrencilerinin kullandığı en sık 1000 kelime (Karadağ, 2018) içinde yer almayan 465 kelime aşağıda alfabetik olarak verilmiştir:

Sadece Sıklık Sözlüğü'ndeki ilk 1000 Kelime İçinde Bulunan Kelimeler (Alfabetik)

$\begin{array}{llll}\text { abi } & \text { anlayış } & \text { bağ } & \text { başkası } \\ \text { açı } & \text { aralık } & \text { bahset- } & \text { başlangıç } \\ \text { açıkla- } & \text { araştırma } & \text { bakan } & \text { başlık } \\ \text { aday } & \text { ardından } & \text { bakanlık } & \text { batı } \\ \text { adet } & \text { artış } & \text { bakım } & \text { bazısı } \\ \text { ağa } & \text { art- } & \text { bakış } & \text { beden } \\ \text { ağır } & \text { asıl } & \text { banka } & \text { belediye } \\ \text { ait } & \text { aş } & \text { barış } & \text { belge } \\ \text { ak } & \text { aşama } & \text { basın } & \text { belirli } \\ \text { aktar- } & \text { aşk } & \text { basit } & \text { belir- } \\ \text { algıla- } & \text { aydın } & \text { baskı } & \text { belli } \\ \text { analiz } & \text { ayır- } & \text { başbakan } & \text { bey } \\ \text { anayasa } & \text { azal- } & \text { başkan } & \text { beyin }\end{array}$




\begin{tabular}{|c|c|c|c|}
\hline biçim & doğrusu & gönül & kabul \\
\hline bilim & doğu & gör & kalem \\
\hline bilinç & dolayısıyla & görev & kalite \\
\hline birer & dol- & görevli & kamu \\
\hline birey & dolu & görüntü & kanal \\
\hline birim & dök- & görüş & kanun \\
\hline birleş- & dönüş- & gözle- & kapa- \\
\hline birlik & duru & güç & kap- \\
\hline bitki & dün & güçlü & kapsam \\
\hline borç & düşük & gündem & kara \\
\hline boyut & düzel- & güney & karşın \\
\hline boz- & düzen & güvenlik & kat \\
\hline bölge & düzey & hafif & katkı \\
\hline böl- & edebiyat & hani & kavram \\
\hline bula- & efendi & harca- & kavuş- \\
\hline cep & eğilim & hastalık & kaydet- \\
\hline ciddi & ek & hat & kayıр \\
\hline cumhuriyet & ekle- & hazır & kayıt \\
\hline cümle & ekonomi & henüz & kaynak \\
\hline çağ & ekonomik & hepsi & kaynaklan- \\
\hline çalışan & elbette & herhalde & kâr \\
\hline çerçeve & ele- & herhangi & kelime \\
\hline çeşit & emir & hesap & kent \\
\hline çevir- & enerji & hesapla- & kesim \\
\hline çıkar & engel & hiz & kesin \\
\hline çıkış & engelle- & hızla & kıl \\
\hline çizgi & esas & hizmet & kısım \\
\hline çoğunluk & etki & hukuk & ki \\
\hline çözüm & etkili & hücre & kimlik \\
\hline dahil & etkinlik & hüküm & kitle \\
\hline dava & eylem & hükümet & koca(eş) \\
\hline daya- & faaliyet & içer- & koku \\
\hline değerlen- & faktör & idare & kolay \\
\hline değişiklik & falan & iddia & kon- \\
\hline değişim & farklılık & ifade & kontrol \\
\hline değ- & felsefe & iktidar & konum \\
\hline demokrasi & firsat & iletişim & koşul \\
\hline dene- & firma & ilginç & köşe \\
\hline denge & fiyat & ilişkin & kredi \\
\hline derece & gazete & ilişti & kriz \\
\hline dergi & geçmiş & ilke & kullanım \\
\hline destek & gelenek & inanç & kurul \\
\hline destekle- & gelir & ince & kuruluş \\
\hline devam & geliş- & incele- & kurum \\
\hline devrim & genel & internet & kuvvet \\
\hline diğeri & geniş & işaret & kuzey \\
\hline dik & gerçekleş- & işçi & kültür \\
\hline dikkat & gerek & işlem & kültürel \\
\hline $\operatorname{din}$ & gerekli & işle- & lazım \\
\hline dizi & girdi & itibar & lider \\
\hline doğal & giriş & itibaren & lira \\
\hline doğrudan & gizli & iz & madde \\
\hline
\end{tabular}




\begin{tabular}{|c|c|c|c|}
\hline mahkeme & öteki & şiddet & vazgeç- \\
\hline makina & öz & şirket & ver \\
\hline mal & özel & tablo & vergi \\
\hline maliyet & özgürlük & tahmin & veri \\
\hline malzeme & parti & takdir & vurgula- \\
\hline meclis & paşa & takip & vücut \\
\hline memur & pay & talep & yağ \\
\hline merak & piyasa & tamamen & yaklaşık \\
\hline merkez & planla- & tamamla- & yaklaşım \\
\hline mesaj & politika & tanım & yalnızca \\
\hline mesele & problem & tanımla- & yana \\
\hline metin & program & tarım & yanit \\
\hline mevcut & proje & tart- & yansı- \\
\hline meydan & rahat & tarz & yapı \\
\hline $\mathrm{mI}$ & rapor & tavir & yarar \\
\hline miktar & rastla- & tedavi & yararlan- \\
\hline millet & rekabet & tehlike & yarat- \\
\hline milletvekili & resmi & teknik & yardımcı \\
\hline milli & risk & teknoloji & yasa \\
\hline model & rol & temsil & yatırım \\
\hline modern & ruh & tepki & yavaş \\
\hline mücadele & sağlık & tercih & yayınla- \\
\hline mümkün & sahne & tespit & yay- \\
\hline müşteri & salon & teşekkür & ya(bağlaç) \\
\hline neredeyse & sanat & ticaret & yerel \\
\hline nitelik & sanatçı & tip & yerleş- \\
\hline nokta & sanayi & toplam & yetenek \\
\hline normal & sapta- & toplantı & yeterli \\
\hline nüfus & satış & topluluk & yetiş- \\
\hline ocak & savun- & toplumsal & yetki \\
\hline okur & sayfa & tost & yetkili \\
\hline ol & sebep & tür & yık- \\
\hline olanak & seçim & uç & yıldız \\
\hline olgu & sektör & ulusal & yıllık \\
\hline olumlu & serbest & uluslararası & yoğun \\
\hline olumsuz & sermaye & umut & yolla- \\
\hline oluş- & seviye & unsur & yorum \\
\hline oran & sık & uygula- & yönelik \\
\hline ordu & Sınır & uygun & yönel- \\
\hline ortak & sistem & uy- & yönetici \\
\hline ortalama & siyasal & uzaklaş- & yönetim \\
\hline ortam & siyaset & uza- & yönet- \\
\hline oy & siyasi & uzan- & yöntem \\
\hline öde- & sorumluluk & uzman & yük \\
\hline öğretim & sosyal & ücret & yüksel- \\
\hline ölçü & sözcük & ünlü & yürek \\
\hline öncelik & sözleş- & üretim & yüzde \\
\hline öneri & suç & üret- & yüzyıl \\
\hline öner- & sun- & ürün & ziyaret \\
\hline önle- & süreç & üstelik & zorla- \\
\hline örgüt & şart & üye & \\
\hline öte & şaş- & vatandaş & \\
\hline
\end{tabular}


Karadağ, Ö. (2019). Neden bir çocuk dili derlemine ihtiyacımız var?. Ana Dili Eğitimi Dergisi, 7(3), 765-780.

Türkçe Sıklık Sözlüğü’ndeki en sık 1000 kelimeden bazılarının çocuklar tarafından bilindiği muhakkak olmakla birlikte yukarıdaki listede yer alan kelimelerin 1-8. sınıf çocuklarının en sık kullandığı 1000 kelime içinde bulunmaması, bu kelimelerin çocuk dünyasında aynı önceliğe sahip olmadığını ortaya koymaktadır. Örneğin yukarıdaki listede yer alan hukuk, yönetim ve ekonomi-piyasa sistemiyle ilgili olan kelimelerin (anayasa, hukuk, kanun, mahkeme, vergi, yasa, bakan, bakanlık, başbakan, başkan, belediye, cumhuriyet, eğilim, ekonomi, ekonomik, güvenlik, kamu, kurul, kuruluş, kurum, kültür, mahkeme, maliyet, milletvekili, nüfus, örgüt, piyasa, politika, program, resmi, sanayi, seçim, sektör, sermaye, siyasal, siyaset, siyasi, ulusal, uluslararası, yetkili, yönetici, yönetim) çocuk dünyasında önceliği olduğunu söylemek mümkün değildir. Liste yer alan kelimeler için kategoriler arttırılabilir. Dolayısıyla Türkçe Sıklık Sözlüğü'nde yer alan ilk 1000 kelimenin ilköğretimde, özellikle alt sınıf düzeyleri olan ilkokulda öğretilmeye çalışılması veya bu listeyi esas alarak metin üretilmesi, metinlerin seviyelendirilmesi mümkün değildir. Liste ayrıntılı olarak incelenirse bunun akademik eğitimin ağılıklı olduğu lise ve üstü eğitim düzeylerine referans olabileceği açıktır. Türkçenin yabancı dil olarak ilkokul ve ortaokul düzeyindeki öğretiminde de aynı durum geçerli olacaktır.

\section{Tartışma, Sonuç ve Öneriler}

Çalışmada Türkçe Ulusal Derlemi (http://www.tnc.org.tr) temelli olarak hazırlanan Türkçe Sıklık Sözlüğü’ndeki (Aksan vd., 2017) ilk 1000 kelime ile temel eğitim düzeyindeki öğrencilerin yazılı anlatımlarında en sık kullandığı 1000 kelime karşılaştııılmıştır. Karşılaştırmada her iki listede 535 kelimenin ortak olduğu tespit edilmiştir. Listeler arasında ortak olan kelimelerin dilin işletilmesinde vazgeçilmez olarak kullanılması zorunlu olan edatlar, temel bağlaçlar, şahıs zamirleri ile temel zarflar, temel sıfatlar, gündelik ihtiyaçlarla ilgili durum ve varlıkları karşılayan isimler olduğu belirlenmiştir.

Çalışmada ikinci olarak sadece temel eğitim düzeyindeki öğrencilerin en sık kullandığı 1000 kelime içinde yer alan kelimeler belirlenmiştir. Bunların genel olarak hayvan adları, oyunlar ve spor dalları, arkadaşlık ve dostlukla ilgili kelimeler, duygular, yiyecekler, eğitim ve okulla ilgili çocuk dünyasına özgü kelimeler olduğu belirlenmiştir.

Çalışmada üçüncü olarak Türkçe Sıklık Sözlüğü’ndeki (Aksan vd., 2017) ilk 1000 kelime içinde bulunan ancak temel eğitim düzeyindeki öğrencilerin en sık kullandığı 1000 kelime arasında yer almayan kelimeler belirlenmiştir. Bunların daha çok yönetim, piyasa-ekonomi, hukuk vb. alanlarına ilişkin kelimeler olduğu belirlenmiştir.

Derlem temelli oluşturulan sıklığa dayalı sözlükler dilin hem ana dili hem de yabancı dil olarak öğretimi bakımından son derece önemli kaynaklardır. Ancak bir dilin ağırlıklı olarak yazılı metinlerinden oluşturulan gerek referans gerekse monitör derleminden elde edilen örneğin en sık 1000-1500 kelimesinin, okul öncesi ve temel eğitim düzeyindeki çocuklara öğretilmesi veya bu kelimelerle bu 
düzeydeki çocukların okuyacağı metinlerin seviyelendirilmesi oldukça zordur. Çocuk diliyle dilin genel kullanımı arasında var olan farklılık, sıklık bakımından önemli bir ayrışmaya sebep olmaktadır. Kuşkusuz dilin genel derleminden elde edilen bir sıklık listesinin ilk 1000 ila 2000 kelimesi ile çocuk dilinden elde edilen bir sıklık listesinin aynı düzeyleri arasında dilin işletilmesi için kaçınılmaz olarak kullanılması zorunlu olan ögeler açısından ortaklıklar söz konusudur. Ortaklıkların özellikle edatlar, bağlaçlar, temel zarflar, şahıs zamirleri, temel sıfatlar, günlük hayatta ihtiyaç duyulan durumlar ve varlıklarla ilgili isimler ekseninde olduğu söylenebilir. Hatta gerek çocuk dilinde gerekse derlem havuzunda en sık kullanılan ilk 50 kelime arasında bu ortaklığın çok daha yüksek olduğu yüzeysel bir karşılaştırmada görülebilir. Aşağıdaki tabloda bu karşılaştırma yapılmaktadır:

Tablo 1. Öğrenci - Derlem IIlk Elli Kelimenin Karşılaştırılması

\begin{tabular}{|c|c|c|c|}
\hline \multicolumn{2}{|c|}{$\begin{array}{l}\text { A Frequency Dictionary of Turkish En Sık } \\
\text { kullanılan } 50 \text { Kelime }\end{array}$} & \multicolumn{2}{|c|}{$\begin{array}{l}\text { Temel Eğitim Öğrencilerinin En Sık } \\
\text { Kullandığı } 50 \text { Kelime }\end{array}$} \\
\hline 1. $\underline{\text { bir }}$ & 26. yer & 1. $\underline{\text { bir }}$ & 26. güzel \\
\hline 2. 으- & 27. bul- & 2. ben & 27. gör- \\
\hline 3. ve & 28. iç & 3. ve & 28. çık- \\
\hline 4. $\underline{\mathrm{bu}}$ & 29. ama & 4. çok & 29. insan \\
\hline 5. $\underline{\text { da }}$ & 30. zaman & 5. $\underline{\mathrm{o}}$ & 30. oyna- \\
\hline 6. et- & 31. her & 6. da & 31. iste- \\
\hline 7. $\underline{o}$ & 32. şey & 7. git- & 32. iyi \\
\hline 8. yap- & 33. kadar & 8. 의- & 33. kendi \\
\hline 9. al- & 34. ara & 9. sonra & 34. okul \\
\hline 10. de- & 35. git- & 10. sev- & 35. ver- \\
\hline 11. ben & 36. en & 11. arkadaş & 36. en \\
\hline 12. gel- & 37. yıl & 12. bu & 37. al- \\
\hline 13. için & 38. değil & 13. gel- & 38. oyun \\
\hline 14. çok & 39. çalış- & 14. anne & 39. daha \\
\hline 15. ver- & 40. iste- & 15. $\underline{\mathrm{biz}}$ & 40. gelecek \\
\hline 16. ne & 41. geç- & 16. ev & 41. onlar \\
\hline 17. daha & 42. bil- & 17. var- & 42. herkes \\
\hline 18. gibi & 43. biz & 18. ora & 43. çalış- \\
\hline 19. gör- & 44. gün & 19. de- & 44. gez- \\
\hline 20. kendi & 45. insan & 20. baba & 45. yemek (aş) \\
\hline 21. mı (soru eki) & 46. anla- & 21. yer & 46. ye- \\
\hline 22. var- & 47. ya (bağlaç) & 22. gün & 47. kız \\
\hline 23. çık- & 48. el & 23. için & 48. çocuk \\
\hline 24. ile & 49. ki & 24. ama & 49. kadar \\
\hline 25. sonra & 50. kal- & 25. yap- & 50. ne \\
\hline
\end{tabular}

Tabloda 30 kelimenin her iki listede de ortak olarak yer aldığı görülmektedir. Ortak kelimeler altı çizili olarak gösterilmiştir. Ancak listelerin ilerleyen sıralarında ayrışma başlamaktadır. Çocuk dünyasında var olan hayvan adları, oyunlar ve spor dalları, arkadaşlık ve dostlukla ilgili kelimeler, duygularla ilgili kelimeler, yiyecekler, eğitim ve okulla ilgili kelimeler çocukların anlatımlarından elde edilen bir sıklık listesinde ilk 1000 kelime içinde yer alırken genel derlemden elde edilen bir sıklık listesindeki sıralamaları ilk 1000 kelimenin dışına çıkmaktadır. 


\section{Neden Bir Çocuk Dili Derlemine İhtiyacımız Var?}

Sonuçlar ana dili olarak Türkçe eğitimi bakımından geniş hacimli bir özel çocuk dili derlemine ihtiyaç duyulduğunu ortaya koymaktadır. Alt derlemleri okul öncesi, ilkokul ve ortaokul şeklinde tasarlanacak bir özel derlem ana dili olarak Türkçe eğitiminde önemli bir kaynak oluşturacaktır. Böylesi bir özel derlem çocukların sözlü ve yazılı dilinden oranlı bir seçki üzerine tasarlanmalıdır. Derlemden elde edilecek sonuçlar çocuk edebiyatı yazarları için de temel bir kaynak oluşturacaktır. Çocuklar için metin üreten tüm kesimlere bu derlem rehberlik edecektir. Yanı sıra çocuklara okutulacak metinlerin seviyelendirilmesi bakımından da bu derlem işlevsel olacaktır. Bu aynı zamanda çocukluk çağında Türkçe öğrenen yabancı öğrencilere yönelik olarak önemli bir kaynak oluşturacaktır.

\section{Kaynaklar}

Aksan, D. (2000). Her yönüyle dil ana çizgileriyle dilbilim. Ankara: TDK Yayınları

Aksan, Y., Aksan, M., Mersinli, Ü. \& Demirhan, U.U. (2017). A frequency dictionary of turkish. London and New York: Routledge.

Baş, B. (2006). 1985-2005 yılları arasında çocuk edebiyatı sahasında yazılmıs tahkiyeli metinlerin söz varlığı üzerine bir araştırma. Yayımlanmamış Doktora Tezi. Gazi Üniversitesi, Eğitim Bilimleri Enstitüsü, Ankara.

Çiftçi, M. (1991). Bir grup yükseköğrenim öğrencisi üzerinde kelime serveti araştırması. Yayımlanmamış Yüksek Lisans Tezi. Ankara: Gazi Üniversitesi, Sosyal Bilimler Enstitüsü.

Göz, i. (2003). Yazılı Türkçenin kelime sıklığı sözlügü. Ankara: TDK Yayınları.

İpek Eğilmez, N. (2010). Illköğretim Türkçe ders kitaplarındaki söz varlığının ilköğretim dördüncü sınıf öğrencilerinin yazılı anlatımlarına aktarımı. Yayımlanmamış Doktora Tezi. Bursa: Uludağ Üniversitesi, Sosyal Bilimler Enstitüsü.

Karadağ, Ö. (2005). Illköğretim I. kademe öğrencilerinin kelime hazinesi üzerine bir araştırma. Yayımlanmamış Doktora Tezi. Ankara: Gazi Üniversitesi, Eğitim Bilimleri Enstitüsü.

Kurudayıoğlu, M. (2005). Illköğretim II. kademe öğrencilerinin kelime hazinesi üzerine bir araştırma. Yayımlanmamış Doktora Tezi. Ankara: Gazi Üniversitesi, Eğitim Bilimleri Enstitüsü.

Kurudayıoğlu, M. ve Karadağ, Ö. (2006). Ortak kelime hazinesi kazandırmada ilköğretim sekizinci sınıf Türkçe ders kitaplarının durumu. Ahi Evran Üniversitesi Kırşehir Eğitim Fakültesi Dergisi, 7(2), s.335-343.

Mc Enery, T. and Wilson, A. (2004). Corpus linguistics-an Introduction, (2. Copy). Edinburg: Edinburg University.

Nation, I. S. P. (1990) Teaching and learning vocabulary. Boston: Heinle \& Heinle.

Pilav, S. (2008). Üniversite birinci sınıf öğrencilerinin söz varlığı üzerine bir araştırma. Yayımlanmamış Doktora Tezi. Ankara: Gazi Üniversitesi, Eğitim Bilimleri Enstitüsü.

Lipinski, S. (2010). A Frequency Analysis of Vocabulary in Three First-Year Textbooks of German. Die Unterrichtspraxis/Teaching German 43 (2), 167-174.

Tahiroğlu, B.T. (2010). Bilgisayar destekli sözlük bilimi çalışmalarında dermele sözlüğü veri tabanı örneği (Yayımlanmamış Doktora Tezi). Adana: Çukurova Üniversitesi, Sosyal Bilimler Enstitüsü.

Vardar, B. (2002). Açıklamalı Dilbilim Terimleri Sözlüğü. İstanbul: Multilingual.

Yazı, Z. (2005). Orta öğretim 10. sınıf öğrencilerinin kelime hazinesi üzerine bir araştırma. Yayımlanmamış Yüksek Lisans Tezi. Ankara: Gazi Üniversitesi Eğitim Bilimleri Enstitüsü.

Yiğittürk, H. (2005). Orta öğretim 9. sını öğrencilerinin kelime hazinesi üzerine bir araştırma. Yayımlanmamış Yüksek Lisans Tezi. Ankara: Gazi Üniversitesi Eğitim Bilimleri Enstitüsü. 
https://www.english-corpora.org/bnc/ Erişim tarihi: 01.07.2019

https://www.tnc.org.tr Erişim tarihi: 01.07.2019

\section{Introduction}

Frequency studies are important in teaching mother tongue and foreign language. Frequency is defined as "the number of occurrences of the same linguistic phenomenon or unit in a speech or writing of a certain length (Vardar, 2002). In a frequency study, it is aimed to create a list by determining the number of repetitions of the units in the selected content, and the resulting list moves from the most frequent element to the least frequent element.

For all languages, the first 1000 words used in a language correspond to approximately $80 \%$ of words produced in that language (Aksan 2000). This is similar in studies on content compiled from a book or a social group. According to Rayson and Davis (2008) from Nation (1990), it was found that the most common 4,0005,000 words were $95 \%$ of a written text and the most commonly used 1,000 words were $85 \%$ of speech (Aksan et al., 2017).

Frequency lists obtained from corpora are a basic reference especially in foreign language teaching. Using corpus-based frequency lists or frequency dictionaries is highly functional in general language teaching. The general approach is to teach the most commonly used units in the language. At this point, the most common 1000 to 2000 words from the corpora are used functionally. However, general collections reveal the general appearance of language and this appearance contradicts with developmental characteristics when it comes to words to be taught to children at early ages (preschool and basic education level).

In this study, the first 1000 words of the frequency list obtained from a general Turkish corpus are compared with the first 1000 words of the frequency list obtained from the expressions of children studying at basic education level in order to reveal the characteristics of child language.

\section{Method}

In this study, the most frequently used 1000 words of basic education students were compared with the first 1000 words of corpus-based frequency dictionary. The frequency list of the students at basic education level is based on the first 1000 words of the "Target Word List of 1250 words in the Vocabulary Teaching book prepared by Karadağ (2018). The most frequent 1000 words based on corpus were taken from Aksan et al. (2017) A Frequency Dictionary of Turkish. This study is a frequency dictionary containing 5000 most commonly used words written and spoken in Turkish based on the Turkish National Corpus (http://www.tnc.org.tr). The results were obtained by comparing two different lists. First, the common words in both lists were identified. The results were interpreted and reported directly.

\section{Result and Discussion}

The 1st-8th graders' most frequently used 1000 words were compared with the most frequent 1000 words in A Frequency Dictionary of Turkish by (Karadağ, 2018) Aksan et al. (2017). When two lists were compared, it was found that the number of common words in both lists was 535 . This value reveals that the agreement between the two frequency lists is $53,5 \%$. When the list of common words was examined, it was seen that the list contained prepositions, conjunctions, adverbs, personal pronouns and basic adjectives which were inevitable for the operation of the language. However, words related to daily life were also included in the list of common words.

The most frequently used 465 words that appeared in 1000 words -by the 1st-8th grade students (Karadağ,2018) but didn't appear in the most frequent 1000 words list in A Frequency Dictionary of Turkish by Aksan et al. (2017) - were determined. 1000 most frequent words which are used by 1st-8th grade students, had more words related to animal names, games and sports, friendship and emotions, food, school and education and fairy tale. These words, which were not included in the 1000 most frequent word list of the corpus-based frequency list, reveal the nature of the children's world.

465 words which were present in A Frequency Dictionary of Turkish by Aksan et al. (2017) but were not present in word lists of 1st-8th grade students by (Karadağ,2018) were determined. These words were often related to the law, administration and economy-market system.

The results show that a large volume of children's language corpus is needed in terms of Turkish education as a mother tongue. The sub-corpus will be designed as pre-school, primary and secondary schools and will constitute an important resource in Turkish education as a mother tongue. Such a corpus should be designed on a proportionate selection of children's oral and written language. The results of the review will also provide a basic source for children's literature writers. This corpus will also be functional in terms of adapting text levels to be taught to children. This will also be an important resource for foreign students learning Turkish in childhood. 